\title{
Regional Variations in Entrepreneurial Cognitions: Start-Up Intentions of University Students in Spain
}

\author{
Francisco Liñán $^{\dagger}$, David Urbano ${ }^{\ddagger}$ and Maribel Guerrero ${ }^{\S}$ \\ † University of Seville. Av. Ramón y Cajal, 1, 41018-Seville (Spain). \\ Tel.: +34.954554487. Fax:+34.954551636. Email: flinan@us.es \\ \$ Autonomous University of Barcelona. Bellaterra, 08193-Barcelona (Spain). \\ Tel.: +34.935814298 Fax: +34.935812555. Email: david.urbano@uab.es \\ § Autonomous University of Barcelona. Bellaterra, 08193-Barcelona (Spain). \\ Tel.: +34.935811209. Fax: +34.935812555. Email: maribel.guerrero@uab.es
}




\title{
Regional Variations in Entrepreneurial Cognitions: Start-Up Intentions of University Students in Spain
}

\author{
Francisco Liñán ${ }^{\dagger}$, David Urbano*, ${ }^{\ddagger}$ and Maribel Guerrero ${ }^{\S}$ \\ $†$ Economic Department, University of Seville, Seville, Spain $; \S$ Business Economic Department, \\ Autonomous University of Barcelona, Barcelona, Spain;

\section{Regional Variations in Entrepreneurial Cognitions: Start-Up Intentions of University Students in Spain}

\begin{abstract}
Empirical research has recently paid considerable attention to the role of environmental factors in explaining regional variations in entrepreneurial activity. However, cognitive models have not usually included these factors in their analyses. Therefore, the main objective of this study is to identify some of the environmental cognitive elements that may explain regional differences in start-up intentions. Thus, an Entrepreneurial Intention Model is developed, theoretically based on the Planned Behaviour Approach, Institutional Economic Theory, and Social Capital Theory. The empirical analysis is carried out using structural equation techniques over a sample of 549 last-year university students from two Spanish regions (Catalonia and Andalusia). Results confirm that valuation of entrepreneurship in each region helps explain regional differences in entrepreneurial intentions. As expected, social valuation of the entrepreneur was higher in the more developed region (Catalonia), positively affecting perceived subjective norms and behavioural control. In Andalusia, the influence of perceived valuation of the entrepreneur in the closer environment was more important, affecting attitude towards the behaviour and subjective norms. These results explain some of the differences in the pool of potential entrepreneurs in each region. They also justify the need by public-policy decision-makers to promote more positive entrepreneurial values in relatively backwards regions.
\end{abstract}

Keywords: Regional Variations, Entrepreneurial Cognitions, Start-Up Intentions, Spain

* Corresponding author. Email: david.urbano@uab.cat 


\section{Introduction}

Quite recently, Mitchell, Busenitz, Bird, Gaglio, McMullen, and Morse (2007) presented some central questions in Entrepreneurial Cognition Research in the special issue of the journal Entrepreneurship: Theory and Practice. They suggest that future entrepreneurship research should be centred on social cognitive categories (person, context, cognition and motivation). In the last few years, the concern about understanding the key elements involved in the entrepreneurial process has notably grown. In particular, many studies have focused on entrepreneurial cognitions, defined by Mitchell et al. (2002) as the knowledge structures that people use to make assessments, judgments, or decisions involving opportunity evaluation, venture creation, and growth.

In this sense, there is evidence indicating that the cognitive level is influenced by individual perceptions towards venturing, together with personal, sociological and environmental variables. Thus, an opportunity to better understand entrepreneurship is examining those deep beliefs that are behind the cognitive structures, entrepreneurial attitudes, entrepreneurial intentions and entrepreneurial actions (Krueger 2007). A number of entrepreneurial models have tried to identify the main elements involved in entrepreneurial actions, but they suffer from different limitations. Some of them did not include demographic variables (Krueger, Reilly and Carsrud 2000). Others have not considered environmental factors that play a role in entrepreneurship (Gnyawali and Fogel 1994; Davidsson and Henkson, 2002). Nevertheless, empirical analysis regarding those environmental or institutional factors that may be explaining entrepreneurial variations between countries is largely lacking. Empirical evidence regarding regional differences is somewhat stronger, but theoretically narrower (Delmar and Davidsson 2000; Rotefoss and Kolvereid 2005). On the other hand, several studies have used business and engineering university students as their target population, considering them as potential entrepreneurs (Tkachev and Kolvereid 1999; Luthje and Franke 2003).

In this context, the main objective of this paper is to identify some of the environmental elements that may explain regional differences in start-up intentions. This article develops an entrepreneurial intention model analyzing the motivational factors sustained by the planned behaviour approach (Ajzen, 1991); some propositions of the institutional economic theory (North 1990, 2005) and also some influences from social capital research (Anderson and Jack, 2002, Liñán and Santos 2007). Some of these environmental factors explaining regional differences in start-up intentions could be social climate and individual-perception differences. In this sense, this paper follows North's (1990) ideas regarding informal factors -attitudes, beliefs, values-, because the formal factors -norms, regulations- are broadly equivalent in all Spanish regions (Vaillant and Lafuente 2007). Of course, there may be differences with respect to some specific formal structures, such as financing, advising or some other form of help for potential and nascent entrepreneurs. But, since entrepreneurship promotion is widely accepted by policymakers in the two regions studied, we do not expect these differences to be large. Besides, this paper is an exploratory study centred on the role of shared cognitive values in explaining the individual's entrepreneurial intention. Therefore, we will concentrate our analysis on the cognitive perspective and will consider only an informal institutional point of view. 
To achieve this objective, the empirical analysis carried out has consisted of structural equation models, with perceptions -and particularly intention- as dependent variables. Data have been collected through an entrepreneurial intention questionnaire (EIQ) on 549 last-year university students from two Spanish universities located in different regions. The Autonomous University of Barcelona (UAB) from Catalonia, and the University of Seville (USE) from Andalusia, were selected for the comparison taking into consideration their regional differences. On the one hand, Catalonia is located in the Northeast region of Spain, its GDP per capita was 26124 euros in 2006, and 18.7\% of new Spanish enterprises were created in this region. On the other hand, Andalusia is located in the South, its GDP per capita was 17250 euros, and $14.5 \%$ of new Spanish firms were created there. Despite these differences, both regions share important similarities. Catalonia has a population of 7.1 million inhabitants, whereas in Andalusia it is almost 8.0 million. Both of them have diversified productive structures, with more than 3 million employed people each.

Social differences between these two regions are also substantial. Catalonia has a reputation of having a hard-working population, entrepreneurial spirit and a dynamic economy. On the other hand, Andalusia is seen in the rest of Spain as characterized by a relaxed culture, enjoying traditions and folklore. This has often been associated with its lower levels of entrepreneurship and economic development. The results of this research may be important in helping publicpolicy decision-makers improve the cognitive environmental factors that affect start-up intentions. Following this introduction, the paper is structured in four additional sections: theoretical framework, methodology, results, and discussion and conclusion.

\section{Theoretical framework}

The entrepreneurial intention has been considered as the key element in understanding the new-firm creation process (Bird 1988). In this sense, entrepreneurial research has been conducted following two main lines: the personal characteristics or traits of the entrepreneur; and the influence of contextual factors in entrepreneurship. From this last institutional approach, some entrepreneurial models with a cognitive basis emerged to explain this phenomenon (Mitchell et al. 2000): the Entrepreneurial Event (Shapero and Sokol 1982) and the Theory of Planned Behaviour (Ajzen 1991) appeared as the main theory-driver models. They have been widely adopted by entrepreneurial intention research to analyze potential entrepreneurs.

Shapero's model focuses on the phenomenon of the entrepreneurial event, which is conditioned by perceptions of desirability (the individual value system and social system that the individual is part of) and feasibility (financial support and would-be partners). These perceptions are the product of cultural and social environments and they determine personal choice (Shapero and Sokol, 1982). This model was used or adapted empirically by Krueger, Reilly and Carsrud (2000), Peterman and Kennedy (2003) and others. On the other hand, Ajzen's (1991) model explains how the cultural and social environment affects human behaviour. It is based on the individual's intention, which is the result of three determinants: attitude towards the behaviour, subjective norms and perceived behavioural control. Much research has found empirical support for this theory in the area of entrepreneurship (Kolvereid 1996; Tkachev and Kolvereid 1999; 
Krueger, Reilly and Carsrud 2000; Liñán, 2004; Fayolle and Gailly 2005; Veciana, Aponte and Urbano 2005).

From this point of view, studies reveal that both models overlap in two elements: Shapero's construct of perceived venture desirability is very close to Ajzen's determinants of attitude towards the behaviour and subjective norms; and perceived venture feasibility proposed by Shapero is similar to Azjen's perceived behavioural control (Krueger and Brazeal 1994) and also close to the idea of perceived self efficacy (Bandura 1997). For this reason and based on this terminology, Kruger and Brazeal (1994) constructed the Entrepreneurial Potential Model that has been widely used elsewhere (Crant 1996; Walstad and Kourilsky 1998; Veciana, Aponte and Urbano 2005; Guerrero, Rialp and Urbano 2007; and others). Nevertheless, both approaches have been widely used to study entrepreneurship, and some studies have tried to compare their relative explanatory strengths (Krueger, Reilly and Carsrud 2000). Results have always been consistent with the applicability of the theory of planned behaviour. Nevertheless, some conflicts have arisen from differences in measures used, as there are not standard measurement instruments for entrepreneurial intention and its antecedents (Armitage and Conner 2001; Liñán and Chen 2009; Thompson, 2009).

Exogenous or demographic variables, on the other hand, operate indirectly on intentions, only if they change the decision maker's attitudes (Krueger 2000). Therefore, it is not strange that some of these models do not include them (Krueger, Reilly and Carsrud 2000). Similarly, the inclusion of environmental factors in these intention models is still rare. Relevant environmental factors include legal, institutional and socioeconomic conditions, entrepreneurial and business skills, financial or non financial assistance, and other additional elements depending on the country (Gnyawali and Fogel 1994; Davidsson and Henkson 2002). In this context, based on those antecedents and the weaker evidence about the variations between countries or regions (Delmar and Davidsson 2000), an Entrepreneurial Intentional Model is developed to understand the regional variations of entrepreneurial cognition in Spain. This model is integrated by three types of factors: the motivational factors, the environmental factors, and situational factors (control variables), as explained below.

\subsection{Motivational Factors}

Based on the planned behaviour approach, it could be argued that individuals take their decision to create a new enterprise based on three motivational factors: their attitudes towards the behaviour, their perceived behavioural control, and the subjective norms (Ajzen, 1991; Liñán, 2004).

The attitude towards the behaviour refers to the attractiveness of the proposed behaviour or degree to which the individual holds a positive or negative personal valuation about being an entrepreneur (Ajzen 1991, 2002; Kolvereid 1996). In this sense, the attitude towards the behaviour is an important element concerning the perception of desirability that affects entrepreneurial intention. The second motivational factor is perceived behavioural control; that is, the perceived easiness or difficulty of becoming an entrepreneur (Ajzen 1991). The 
importance of this variable in the new-firm creation process resides in its predictive capacity, as it reflects the perception that the individual will be able to control that behaviour (Ajzen 2002). In this line, this element could be influenced by different processes, such as enactive mastery, role modelling, social persuasion, and judgments (Bandura 1997). Several researchers have used different constructs to measure it, such as Boyd and Vozikis (1994) and Zhao, Hills, and Siebert (2005). These motivational elements have been constantly supported by several empirical studies (Kolvereid 1996; Krueger, et al. 2000; Fayolle and Gailly 2005). Although some researchers have considered this concept as similar to self-efficacy, Ajzen (2002) specifies that it is a wider construct, since it encompasses self-efficacy and perceived controllability of the behaviour.

\section{Hla. Attitude towards the behaviour has a positive impact on entrepreneurial intentions independent from the regional context \\ H1b. Perceived behavioural control has a positive impact on entrepreneurial intentions independent from the regional context}

On the other side, subjective norms measure the perceived social pressure from family, friends or significant others (Ajzen 1991) to perform the entrepreneurial behaviour. It refers to the perception that 'reference people' may or may not approve of the decision to become an entrepreneur (Ajzen 2001). In general, these norms tend to contribute more weakly to intention (Armitage and Conner 2001) for individuals with strong internal locus of control (Ajzen 2002) than for those with a strong action orientation (Bagozzi 1992). In the entrepreneurship literature, several studies found no significant direct relationship between subjective norms and entrepreneurial intention (Autio, Keeley, Klofsten, Parker and Hay, 2001; Krueger et al., 2000). Social capital literature finds evidence indicating that these norms favourably affect the attitude towards the behaviour and the perceived behavioural control (Scherer, Brodzinsky and Wiebe 1991; Cooper 1993; Matthews and Moser 1996; Kennedy, Drennan, Penfrow, and Watson, 2003; Liñán and Santos 2007). Thus, our second set of hypotheses is:

H2a. Subjective norm has a positive impact on the attitude towards the behaviour independent of the regional context

H2b. Subjective norm has a positive impact on the perceived behavioural control independent of the regional context.

\subsection{Environmental Factors}

According to the Social Learning Theory, environmental factors have a great influence over learning and higher cognitive processes (Bandura 1977). Thus, behaviours would be the result of environmental stimuli. Environmental factors, according to North (1990, 2005), include both formal and informal elements. And both of them may play a role in the configuration of entrepreneurial intentions. However, this paper focuses on the analysis of the role played by one specific kind of informal factor: the valuation of entrepreneurship in the individual's closer and wider environments. In this sense, many authors point out that institutional economic theory serves to analyze the influence of environmental factors on entrepreneurship. Thus, this theory has been applied to the analysis of new firm creation in transition economies (Nee and Young 
1991; Nee 1992; Litwack 1993; Brautigam 1997; Peng and Shekshnia 2001; Stein, 2002). Similarly, it has also been used in the case of Western European areas (Westhead 1995; Veciana 1999; Díaz, Urbano and Hernández 2005; Veciana, Aponte and Urbano 2005; Urbano, 2006).

In this line, many entrepreneurship researchers have stressed the role of cultural variations in explaining differential entrepreneurial behaviours across countries and regions (Davidsson 1995; Mueller and Thomas 2001; Hayton, George, and Zahra 2002). Spilling (1991) considers culture as the common ideas, values, and norms inside a group of people. As a consequence, these values could influence the entrepreneurship level of a society by legitimating or promoting on individuals certain positive attitudes related to firm creation (Davidsson 1995). Informal institutional factors, therefore, would reflect the social dynamics of entrepreneurship, where the level of entrepreneurial activity within a community is an unintended consequence of many individual choices with respect to entrepreneurship (Bygrave and Minniti 2000). These choices, however, could be derived from social models that impact on the individual's entrepreneurial intention (Hmieleski and Corbett 2006).

These shared values and ideas are transmitted through human interaction and network contacts at different levels. Thus, according to Naphiet and Ghoshal (1998), they would represent the cognitive dimension of social capital. Until now, the role of structural social capital in the form of personal networks has been studied as an important element in the creation and development of entrepreneurial firms (Jack and Anderson, 2002; Hoang and Antoncic, 2003; Greve and Salaff, 2003). This may be due to the fact that structural social capital is a relatively objective and externally observable dimension. Cognitive social capital (CSC), instead, derives from mental processes and resulting ideas, reinforced by culture and ideology, generating values, attitudes, beliefs and trust (Naphiet and Ghoshal, 1998), and has received much less attention.

However, the strength of the linkages with other individuals or organizations depends on the frequency and proximity of contact between individuals. Granovetter $(1983,1985)$ was the first to differentiate between strong and weak ties. Both strong ties (among members of a family or ethnic group) and weak ties are complementary for an efficient development of social capital (Woolcock and Narayan, 2000). In this sense, we can talk about bonding social capital, derived from strong intra-community ties, and bridging social capital, derived from weak extracommunity ties. Both categories are the result of the relational dimension of social capital (Naphiet and Ghoshal, 1998). From a cognitive perspective, both bonding and bridging social capital could play different roles in transmitting values and ideas that may have an influence on perceptions and, through them, on intentions (Simon, Houghton and Aquino, 1999; Carolis and Saparito, 2006).

Firstly, bonding cognitive social capital, based on strong ties with family or friends, generates different values, trust, shared languages and shared narratives. Thus, individuals receive the influence from Closer Environment Valuations, and this contributes to the generation of more favourable perceptions towards start-up (Cooper and Dunkelberg, 1987; Scherer, Brodzinsky and Wiebe, 1991; Kuratko and Mathews, 2004; Kim, Aldrich and Keister, 2006). They could exert their influence directly on attitude towards the behaviour as a consequence of the cognitive values and beliefs conforming individual's perceptions towards a career (Uphoff 2000; Grootaert and Bastelaer 2001). Kennedy et al. (2003) found that expectations from family, friends and 
significant others are key variables influencing student's responses, and that closer environment expectations were related to attitude towards the behaviour, subjective norms and gender. Perceived behavioural control would not be important at this stage.

Secondly, bridging cognitive social capital based on weak ties could also generate favourable values and beliefs towards firm start-up through the acquisition of information and experience (Jack and Anderson, 2002; Hoang and Antoncic, 2003). Thus, Social Valuation of Entrepreneurship takes a critical role in determining entrepreneurial behaviour (Zahra, Jennings and Kuratko 1999). The underlying system of values pertaining to a specific group or society shapes the development of certain personality traits and abilities, modelling normative and ability perceptions towards the entrepreneurial activity (Thomas and Muller 2000). For example, Takyiasiedu (1993) found that some socio-cultural factors hindered the entrepreneurial activity in Africa.

In this sense, we can now present our third set of hypotheses regarding the effect of environmental valuations of entrepreneurship:

H3a. Closer valuation has a positive impact on the attitude towards the behaviour, but is different depending on the regional context

$H 3 b$. Closer valuation has a positive impact on subjective norms, but is different depending on the regional context

H3c. Social valuation has a positive impact on subjective norms, but is different depending on the regional context

H3d. Social valuation has a positive impact on perceived behavioural control, but is different depending on the regional context

\subsection{Control Variables}

Control variables refer to demographic information (role models, age, gender, educational level or previous work experience). In the literature these variables have been used to define a profile of a typical entrepreneur (Robinson, Stimpson, Huefner, and Hunt, 1991). Some examples reveal the character of these relations: the influence of gender on attitudes towards new enterprise creation (Kolvereid 1996; Mazzarol, Volery, Doss and Thein, 1999); the relationship between gender and self-efficacy (Zhao, Hills and Siebert, 2005); the influence of role models on self-efficacy and possibly on personal attraction and subjective norms (Scherer, Brodzinsky and Wiebe 1991; Carsrud 1992; Boyd and Vozikis 1994); age or labour experience as factors affecting a person's propensity to start a firm (Robinson et al. 1991; Cooper 1993); and the relevance of experience and social influences (Davidsson 1995; Kolvereid 1996). Additionally, some authors point to the higher entrepreneurial activity by immigrants (Bauder, 2008). In this sense, we have considered the inclusion of six control variables in the analysis: age, gender, labour experience, self-employment experience, role models, and being an immigrant.

Insert Figure 1 around here 
In summary, the elements and relationships integrating the Entrepreneurial Intention Model proposed in this paper are presented in Figure 1.

\section{Methodology}

The empirical analysis has been carried out on a sample of last-year university students. This is a convenience sample very often used in entrepreneurship research (Fayolle and Gailly 2005; Kolvereid 1996; Krueger, Reilly and Carsrud 2000; Tkachev and Kolvereid 1999; Veciana, Aponte and Urbano 2005). In particular, recent research has found that young university graduates (25-34 years) show the highest propensity towards starting up a firm (Bosma, Jones, Autio and Levie, 2008).

Then, as our purpose was to analyze social values and their influence on entrepreneurial intentions, two different regions were selected for the analysis. In this context, a brief summary of the main characteristics of both regions is presented in table 1. Catalonia has traditionally been considered as a main Spanish industrial centre. It has also been able to develop a modern services sector. Catalonia produces $18.6 \%$ of the total Spanish GDP, creating $17.8 \%$ of total employment. Therefore, it is characterized by having relatively high productivity. Over the years it has attracted a great number of immigrants from other parts of the country. Nowadays, it represents $16 \%$ of the total Spanish population, with an income level above the national average (118\%). Regarding the entrepreneurial potential, the number of existing and newly-created firms roughly corresponds to its contribution to GDP.

\section{Insert Table 1 around here}

Andalusia, on the other hand, lacks a strong industrial base. In contrast, agriculture, construction and personal services are relatively more developed in the region. Therefore, it specializes in low productivity sectors, since it produces $13.9 \%$ of total Spanish GDP, while generating $14.6 \%$ of employment. It is characterized by having a large total population (17.8\% of Spain), with relatively low income levels ( $78 \%$ of the Spanish average). In Andalusia there is a relatively large number of firms $(16.1 \%)$, but they tend to be smaller. Newly-created firms represent $14.5 \%$ of the Spanish total.

\section{Insert Table 2 around here}

In this study, one large public university in the biggest metropolitan area of each region was chosen: Universitat Autonoma de Barcelona (UAB, in Catalonia) and Universidad de Sevilla (USE, in Andalusia). The main characteristics of both universities are summarized in Table 2. Empirical data for this research were obtained from a total population of 3811 university students (in the two final years of their degrees), during the academic year 2006-2007 (2338 students from UAB and 1473 students from USE). Questionnaires were administered optionally to lastyear students enrolled on business and economics degrees during a class session, with previous professor's authorization. The fieldwork was carried out in October and November 2006. In that environment, response rate was very high, well above $90 \%$. Only a small number of them were 
incomplete or lacked consistency, and were therefore rejected. A few others had a small proportion of missing data, but they were always less than $2 \%$ of items. They were therefore retained.

The final sample was made up of 549 usable questionnaires, 300 of them were from UAB and 249 from USE. The sample error was, therefore, $\pm 3.87 \%$ at a $95 \%$ confidence level $(\mathrm{Z}=1.96$, $\mathrm{p}=\mathrm{q}=0.5$ ). Nevertheless, questionnaires with missing data have been left out for the specific analysis of some items in which data were lacking.

The Entrepreneurial Intention Questionnaire (EIQ) used for this study is a modified version of the one used by Liñán and Chen (2009). Most empirical analyses of entrepreneurial intentions have developed their own ad hoc research instruments (Chandler \& Lyon, 2001). Comparisons between these works become quite problematic, since differences among construct measures are sometimes substantial (Thompson 2009). The EIQ is a newly developed questionnaire based on the existent theoretical and empirical literature about the application of the theory of planned behavior to entrepreneurship. Thus, it has been carefully cross-checked with those instruments used by other researchers, such as Kolvereid (1996), Kolvereid and Isaksen (2006), Chen, Greene, and Crick (1998), Kickul and Zaper (2000), Krueger et al. (2000) or Veciana et al. (2005). Along the whole construction process, Ajzen's (1991, 2001 and 2002) work has been carefully revised to solve any discrepancy that might have arisen between the different instruments. The EIQ is available from the authors upon request. Items used to capture the central elements of the Entrepreneurial Intention Model are included in the appendix.

In their study, Liñán and Chen (2009) recognized some possible problems with the EIQ, such as acquiescence bias. Acquiescence is the tendency of individuals to agree with statements in a scale or instrument, and has been traditionally considered as a characteristic of the measurement instrument used (Ray, 1979; Ferrando, Condon, and Chico., 2004). The more widespread solution is the construction of balanced scales, which are usually made up of Likert-type items. In a balanced scale all the item stems are positively worded; however, half of the items measure in one direction of the trait whereas the other half measure in the opposite direction (Thompson 2009). The main assumption of this type of measures is that acquiescence to the items in one direction will be cancelled out by acquiescence to the items in the opposite direction. So, the sum of the appropriately reversed item scores (content score) is expected to be reasonably free of acquiescence (Hofstee, Ten Berge, and Hendriks, 1998; Nunnally, 1978; Ray, 1983). For this reason, a modified version was used, in which some reversed items were included. In this form, we expect to minimize the possible existence of this statistical problem.

Two encompassing scales have therefore been constructed. In both cases, we have included together the individual scales measuring key theoretical constructs. These items were intermingled and randomly ordered to minimize response-set bias and the halo effect, two common drawbacks of entrepreneurship research instruments (Zahra and Wiklund, 2002). Thus, items A1 to A20 measure the four central constructs of the theory of planned behaviour: Entrepreneurial Intention (A4, A6, A9-reversed-, A13, A17 and A19-rev-), Attitude towards the behaviour (A2-rev-, A10, A12-rev-, A15 and A18), Perceived Behavioural Control (A1, A5-rev, A7, A14, A16-rev-, A20) and Subjective Norms (A3, A8, A11). On the other hand, social values regarding entrepreneurship were measured by an 8-item scale (C1-C8). Three of these 
items measure the valuation of entrepreneurship in the closer environment of the respondent $(\mathrm{C} 1$, $\mathrm{C} 4$, and C7); we have called this construct Closer Valuation. The remaining items measure perceptions regarding general Social Valuation of entrepreneurship (C2, C3-rev-, C5-rev, C6, C8-rev-).

\section{Results and discussion}

As a first step, we carried out both exploratory factor analyses on questions A and C. These factor analyses help explain the variability among observable variables and served to eliminate the items that do not load on the expected factor for this sample. Thus, items remaining after this depuration would be selected to build each of the constructs used in the structural equation model. For example, the 20 items in question A were included together. Since four of the items did not load on the expected factor, they were eliminated. A new factor analysis was performed for the 16 remaining items. Table 3 presents factor loadings, communalities and Cronbach's alphas. The Kaiser-Meyer-Olkin (KMO) measure of sampling adequacy was notably high (0.872), and the Bartlett's test of sphericity was highly significant $(\mathrm{p}<0.001)$. Both measures suggest factor analysis to be an adequate instrument to use. Cumulative variance explained was $61.7 \%$. All items loaded on the expected factor. The only controversial result regards item A15. It corresponds conceptually to factor four (attitude towards the behaviour), but it also loads on factor 1 (intention). Nevertheless, the loading is higher on factor $4(0.514$ vs. 0.424$)$. As this is a first application of this questionnaire (EIQv3), we have decided to keep it. For the future, the wording of some items may need revising.

\section{Insert Table 3 around here}

Social-value items (question C) were also factor-analyzed. Two factors with eigenvalues greater than 1 were initially identified, but interpretation of the factors was not straight-forward. After analyzing basic statistics, item C8 showed a very low level of communality with the other variables. It was therefore eliminated from the analysis. Running the factor analysis again, KMO measure was 0.667 (higher than the usual 0.5 threshold), and Bartlett's test was highly significant $(\mathrm{p}<0.001)$. Cumulative variance explained was $57.2 \%$. Table 4 presents the results of the factor analysis, together with communalities and Conbach's alphas. As may be seen, items C2 and C6 load slightly over the 0.30 threshold on factor 1, though its main contribution is to factor 2. For this reason, we decided to include them in the second factor. Nevertheless, the characteristics of this second factor are not so sound, as shown by the low Cronbach's alpha. Therefore, its inclusion into the Structural Equation Model should be made with caution. In any event, the interpretation of these results could be as follows: Factor 1 = perceived valuation of entrepreneurship in the closer environment (closer valuation). Factor 2 = perceived social valuation of entrepreneurship.

\section{Insert Table 4 around here}

As a next step, we tried to check whether there were statistical differences among the Catalonian and Andalusian sub-samples. The t-test for the equality of means was performed on 
the six factors obtained (entrepreneurial intention, attitude towards the behaviour, perceived behavioural control, subjective norms, closer valuation and social valuation) and the control variables (labour experience, self-employment experience, family role-model entrepreneur, friend entrepreneur, boss entrepreneur, other role-model entrepreneur, age, gender and immigration). Additionally, as a test of possible differences in access to formal support instruments in both regions, a scale was included to measure respondents' knowledge of these assistance measures. Differences were significant in two of the constructs (perceived behavioural control and social valuation of entrepreneurship), and five of the control variables (labour experience, self-employment experience, immigrant, boss entrepreneur and other entrepreneur), as shown in Table 5.

\section{Insert Table 5 around here}

Besides, a difference was also found with regard to knowledge of formal support measures. This test has been included to account for the possible existence of different formal environmental factors in each region, which could affect individuals' intentions. Results show that students in the most developed region (UAB sample) have a slightly but significantly lower level of knowledge of these formal measures. Nevertheless, average intention level is higher for these students (although not significant). In our opinion, this may mean that USE students face a more unfavourable informal environment for entrepreneurship (see below), and try to compensate this by approaching formal support bodies to a greater extent.

A greater number of students in Seville (16\%) than in Barcelona (10\%) come from a different region or from abroad. This may be explained by the scarcity of alternative universities in Southern Spain, at least until very recently. For that reason, a number of students from neighbouring regions may decide to study at USE. In all other instances, the UAB sample had a significantly higher mean. For our analysis, the fact that students in Catalonia see themselves as having a greater perceived behavioural control and perceive a more favourable social valuation of entrepreneurship in their region is especially relevant. UAB students do have a much larger experience. $90 \%$ of them have labour experience (55\% at USE). Similarly, $8 \%$ of students in Barcelona have self-employment experience (3\% at USE). Regarding the presence of role models, there are no significant differences with respect to the most common ones: family and friends. However, UAB students know significantly more role models who are their bosses (42\%, for $22 \%$ in USE) or other different people (30\%, for $21 \%$ in USE).

\subsection{Structural equation model}

The structural equation technique has been increasingly used in behavioural sciences over the last decade (Shook, Ketchen, Hult, and Kacmar, 2004). In this study it has been performed using Partial Least Squares, with PLSGraph 3.0 Build 1126 as the software package (Chin and Frye 2003). The tested model was presented in Figure 1. Constructs have been defined as the factor analyses suggested. The partial least squares technique offers results regarding the structural model (the hypothesized relationships) and also with respect to the measurement model (reliability and validity of scales). Thus, partial least square estimates their own factor loadings, for which constructs reliability and convergent validity should be analyzed again (Burnkrant and 
Page, 1982; Shook et al., 2004). In this case, when performing the full model analysis, some of the items loading in each construct's scales had reliability problems. It is commonly assumed that items comprising each construct should present loadings above 0.707, but a level above 0.6 might be acceptable for newly developed measures (Roldán and Leal 2003). Assuming this criterion, items A2-rev-, A16-rev-, C3-rev- and C5-rev- were eliminated.

\section{Insert Table 6 around here}

Table 6 presents results after eliminating these four items. Reliability has also been computed by the more traditional Cronbach's $\alpha$ and by the item-to-total correlation (Nunnally, 1978). The alpha values obtained are higher than 0.700 in most constructs (only one has an alpha of 0.624), and the item-to-total correlations are positive and significant (between 0.719 and 0.888). Therefore, our proposed constructs may be considered as sufficiently reliable, measuring the information for which they were designed (Chandler and Lyon, 2001). The convergent validity analysis shows whether items integrating each construct -which should be closely related- are actually related. In this sense, the correlation coefficient values obtained range from 0.297 to 0.717, being positive and statistically significant. Thus, items show a sufficiently high relationship with their own constructs (Cohen, 1988).

\section{Insert Figure 2 around here}

After this further depuration, the model was run again. Significant path coefficients are shown in Figure 2, whereas Table 7 presents factor loadings for the different constructs. As may be seen, the theory of planned behaviour is fully corroborated in this case. Hypotheses H1a, H1b, $\mathrm{H} 2 \mathrm{a}$ and $\mathrm{H} 2 \mathrm{~b}$ are confirmed. Besides, there is a significant path coefficient between Subjective Norms and Entrepreneurial Intention. This latter relationship was not found in previous studies (Krueger, Reilly and Carsrud 2000; Autio et al., 2001; Liñán and Chen 2009). For this reason we did not include it as a hypothesis. It is probably the larger sample size which has made this weaker relation show up as significant in our study. As will be shown below, this relationship is significant for neither sub-sample (UAB and USE).

\section{Insert Table 7 around here}

Hypotheses $\mathrm{H} 3$ can be partially confirmed with the results from the joint sample. Valuation of entrepreneurship in the closer environment (Closer Valuation) has significant positive effects over Attitude towards the behaviour and Subjective Norms, as it was assumed in the theory section. An additional non-hypothesized relationship was found from Closer Valuation to Entrepreneurial Intention. This would mean that, independently from their attitude or behavioural control, those individuals whose closer environment values entrepreneurship more positively will have a higher start-up intention. On the other hand, Social Valuation has a significant effect over subjective norms and perceived behavioural control, as hypothesized above.

Results for both sub-samples have been considered separately. Figures 3 and 4 present the results for UAB and USE students. In the first place, it has to be said that Hypotheses $\mathrm{H} 1$ and $\mathrm{H} 2$ fully hold on both instances, adding robustness to the joint results. The effect of subjective norms 
over entrepreneurial intention is not significant in any of the two sub-samples. This is possibly due to this relation being very weak, and only found when sample size is considerably large.

\section{Insert Figure 3 around here}

In the UAB sample, perceived social valuation of entrepreneurship has a much stronger influence on intention, through its effects over subjective norms and perceived behavioural control. On the other hand, perceived closer valuation only affects the level of attitude towards the behaviour. In the USE sample, conversely, this latter variable has a much stronger influence, as it affects the attitude towards the behaviour, subjective norms and entrepreneurial intention directly, whereas social valuation only affects perceived behavioural control. Regarding our Hypotheses, H3a and H3d hold for both sub-samples and path coefficients are broadly similar. Therefore, they are only partially supported. That is to say, they positively affect the specific motivational factor considered, but there is no differential effect between both sub-samples. On the other hand, Hypotheses $\mathrm{H} 3 \mathrm{~b}$ and $\mathrm{H} 3 \mathrm{c}$ hold for only one of the sub-samples. As they also hold for the joint sample, we should consider that the existence of a positive but differential effect is fully confirmed. That is, there is a positive effect in both cases, but it is much stronger (becoming significant) in one of the sub-samples than in the other.

\section{Insert Figure 4 around here}

As indicated above, social valuation of entrepreneurship is significantly higher in Catalonia (UAB) than in Andalusia (USE). A possible explanation might be related to the different spatial reference. In Catalonia there is a considerable sense of 'regional identity' or 'nationality'. Therefore, it may very well be the case that UAB students have answered question $\mathrm{C}$ considering Catalonia as their regional reference, whereas most probably, all USE students have considered Spain as their reference. Anyhow, the relevant fact is that the UAB sub-sample perceives a better social valuation of entrepreneurship.

As a first idea, it may be said that among UAB students, the effect of social valuation is greater. In both sub-samples, it contributes to making respondents feel more able. At UAB, it also makes students feel higher approval if they were to start a firm (subjective norms). On the other hand, it seems that USE students are more highly influenced by the valuation of entrepreneurship in their closer environment. Both in UAB and USE, a better closer valuation of entrepreneurship leads to higher attitude towards the behaviour. However, at USE, it also leads to higher perceptions of approval and higher intention. Therefore, subjective norms seem to be specially influenced by differences in social and closer valuations of entrepreneurship. That is, the perceived support for the start-up decision depends more on social valuation where this latter variable is more favourable. Conversely, it is highly influenced by the closer valuation where social perceptions are relatively negative.

Regarding the role of control variables, all but one makes at least one significant contribution to explaining the constructs. The only exception is self-employment, despite the wide literature supporting its role in the start-up process. Our impression is that the share of respondents with this experience was too low to find significant contributions. Apart from this, two other results deserve attention. Firstly, being an immigrant (being born outside the region) contributes to 
higher levels of both PBC and closer valuation. These relationships are stronger for Andalusia (in the Catalonian sub-sample they are not significant). This leads us to think that immigrants come from regions or countries were entrepreneurship is more often thought of as a valid career option, and they are more familiar with this alternative. In this sense, it has to be remembered that Catalonian students in general had a significantly higher PBC than those of Andalusia. In this respect, it is reasonable to assume that immigrants would find their families (closer environment) value entrepreneurship more than the local Andalusian population.

Secondly, knowing a role-model contributes to higher valuation of entrepreneurship in the closer environment. This is understandable since role-models most often belong to this closer environment. Nevertheless, role-models also have a direct effect on intention, though a weak one (path coefficient is 0.065). This is against the theory, as perceptions alone should suffice to explain the entrepreneurial intention. A further comment on this anomalous result is included in the following section.

Finally, regarding the instrument (EIQv3), a few items had to be eliminated as a consequence of the factor or reliability analyses. In particular, all but one reversed items were removed. These reversed items were intended to prevent acquiescence bias. However, respondents seem to answer them differently because of their negative character. In this sense, some further modifications are probably needed in the questionnaire.

\section{Discussion and Conclusions}

This paper has shown some interesting results regarding the influence of social values on entrepreneurial cognitions. According to them, it could be argued that perceptions regarding general-society and closer-environment values do have an influence on motivational factors determining the entrepreneurial intention.

Nevertheless, this influence would be different in at least two aspects. Firstly, closer valuation of entrepreneurship seems to exert a stronger influence over personal attitude towards the behaviour (desirability, in Shapero's words). Meanwhile, social valuation affects perceptions regarding behavioural control (feasibility). Secondly, these effects are different depending on the region. The most developed area (Catalonia) presents a more favourable social valuation of entrepreneurship, as was expected. In this region, social valuation seems to exert a stronger influence over motivational factors (especially subjective norms). In Andalusia, where social valuation is relatively negative, support for the start-up decision would basically be found within the closer environment.

One important implication of this difference is that in Catalonia the influence of social valuation spreads over the general population. Everybody can benefit from it, feeling higher PBC and subjective norms and, through them, higher intention to start-up. In Andalusia, instead, this positive influence on intentions is not general. Only some individuals will benefit from it (those belonging to families or social groups in which entrepreneurship is highly valued). The supply of potential entrepreneurs would consequently be much smaller. In particular, immigrants have traditionally constituted a very important pool of successful entrepreneurs in Andalusia. 
Therefore, the relevance of promoting more positive entrepreneurial culture and values in relatively backward regions could be highlighted (Guzmán and Santos 2001; Vaillant and Lafuente 2007).

The direct effect found from role models and closer valuation on entrepreneurial intention deserves further analysis. The theory of planned behaviour (Ajzen, 1991; 2001; 2002) states that the motivational antecedents explain intention, whereas all other variables would only have an indirect effect. Against this strong theoretical argument, it is not unusual to find empirical research reporting one or more of these direct relationships (Autio et al. 2001, Choy, Kuppusamy and Jusoh 2005). In this sense, the first and most probable explanation would be the limitations of our research design. Alternatively, the existence of moderating or mediating effects could help explain these direct effects on intention. Thus, role models (especially for the UAB subsample) and closer valuation (especially for the USE subsample) would be moderating the effect of the motivational antecedents on intention. Further research is needed to clarify this point.

The present research has a number of limitations that should be recognized and addressed in future research. In the first place, improvements regarding the instrument are probably needed. Some items may need revising or even elimination. In particular, reversed items have probably been useful to avoid acquiescence bias, but contributed very little to the constructs. Additionally, some unexpected results were found, such as the significant effect of some variables on intention, which may be partly attributed to measurement issues. The model used in the analysis differs from the original TPB model in some minor points. This decision was made based on previous results and meta-analyses (Armitage and Conner 2001, Chandler and Lyon 2001, Liñán and Chen 2009). In particular, the measure used for subjective norm is simpler than that of Ajzen's (1991). However, additional research should be specifically designed to compare both views and confirm or reject these deviations.

Secondly, more work will be needed to fully understand how perceived values in each regional culture help determine start-up decisions. A number of interesting environmental-factor elements should be analyzed. For example, the influence that formal factors (e.g. physical infrastructures or incubators, formal sources of funding, non-monetary helps, among others) implemented in each region improving the entrepreneurial culture.

Thirdly, the influence of university actions towards entrepreneurship needs to be considered. In this respect, some questions need to be incorporated to obtain complementary data that allows identifying how entrepreneurial educational courses or other support programs in each university would impact on the people's schemes. Thus, the relationship between university culture and student's entrepreneurial intentions deserves also closer attention.

Fourthly, it is necessary to apply this methodology to different samples. In particular, since most support measures to entrepreneurship in Spain are focused on the development of high-tech firms, engineering schools, technology-park workers, and similar 'potential technology entrepreneurs' should be analyzed. 


\section{Acknowledgements}

A previous version of this paper was presented at the 2007 Babson Conference (Madrid, Spain). We are most grateful to several participants for their comments and suggestions, which have contributed to the improvement of this study. In particular, we highly appreciate comments from Norris F. Krueger. We are also grateful to comments and suggestions by two anonymous reviewers, which have decisively contributed to improve this final version of the manuscript. Of course, any errors that may remain are the sole responsibility of the authors.

This research has been partly financed from the following sources: Maribel Guerrero has received financial support from Autonomous University of Tamaulipas (Mexico); David Urbano has received financial resources from SEJ2007-60995 (Spanish Ministry of Education and Science) and 2005SGR00858 (Catalan Government's Department for Universities, Research and Information Society).

\section{References}

Ajzen, I. 1991. The Theory of Planned Behaviour. Organizational Behaviour and Human Decision Processes 50(2): 179-211.

Ajzen, I. 2001. Nature and operation of attitudes. Annual Review of Psychology 52: 27-58.

Ajzen, I. 2002. Perceived behavioural control, self-efficacy, locus of control, and the theory of planned behaviour. Journal of Applied Social Psychology 32(4): 665-683.

Anderson, A. and S. Jack. 2002. The articulation of social capital in entrepreneurial networks: a glue or a lubricant?. Entrepreneurship \& Regional Development 14(3): 193-210.

Armitage, C. J., and M. Conner. 2001. Efficacy of the theory of planned behaviour: a meta-analytic review. British Journal of Social Psychology 40(4): 471-499.

Autio, E., R. H. Keeley, M. Klofsten, G. G. C. Parker, and M. Hay. 2001. Entrepreneurial intent among students in Scandinavia and in the USA. Enterprise and Innovation Management Studies 2(2): 145160.

Bagozzi, R. P. 1992. The Self-Regulation of Attitudes, Intentions, and Behaviour. Social Psychology Quarterly 55(2), 178-204.

Bandura, A. 1997. Self-efficacy: The exercise of control. New York: Freeman.

Bauder, H. 2008. Explaining Attitudes towards Self-employment among Immigrants: A Canadian Case Study. International Migration 46(2): 109-133.

Bird, B. 1988. Implementing entrepreneurial ideas: the case for intention. Academy of Management Review 13: 442-453.

Bosma, N., K. Jones, E. Autio, and J. Levie. 2008. Global Entrepreneurship Monitor 2007, Executive Report. USA: London Business School and Babson College.

Boyd, N. G., and G. S. Vozikis. 1994. The influence of self-efficacy on the development of entrepreneurial intentions and actions. Entrepreneurship Theory and Practice 18: 63-77.

Brautigam, D. 1997. Substituting for the State: Institutions and Industrial Development in Eastern Nigeria. World Development 25(7): 1063-1080.

Burnkrant, R.E., and T.J. Page. 1982. An examination of the convergent, discriminant and predictive validity of Fishbein's behavioral intention model, Journal of Marketing Research 19(4): 526-550.

Bygrave, W., and M. Minniti. 2000. The Social Dynamics of Entrepreneurship. Entrepreneurship Theory and Practice 24(3): 25-36.

Carolis, D.M. and P. Saparito. 2006. Social Capital, Cognition, and Entrepreneurial Opportunities: A Theoretical Framework. Entrepreneurship Theory and Practice 30(1): 41-56.

Carsrud, A. L. 1992. The Psychology of Entrepreneurship. Stirling: University of Stirling. 
Chandler, G. N., and D. W. Lyon. 2001. Issues of Research Design and Construct Measurement in Entrepreneurship Research: The Past Decade. Entrepreneurship Theory and Practice 25(4): 101113.

Chen, C.C., P.G. Greene, and A. Crick. 1998. Does entrepreneurial self-efficacy distinguish entrepreneurs from managers?, Journal of Business Venturing 13(4): 295-316.

Chin, W. W., and T. Frye. 2003. PLS-Graph, Version 3.00 (Build 1126). Houston: University of Houston.

Choy, C. S., J. Kuppusamy, and M. Jusoh. 2005. Entrepreneurial careers among business graduates: Match-making using theory of planned behavior. International Journal of Entrepreneurship, 9: 6790.

Cohen, J. 1988. Statistical power analysis for the behavioral sciences. NJ: Lawrence Erlbaum.

Cooper, A.C. and W.C. Dunkelberg. 1987.Entrepreneurial Research: Old Questions, New Answers and Methodological Issues. American Journal of Small Business

Cooper, A. C. 1993. Challenges in Predicting New Firm Performance. Journal of Business Venturing 8(3): 241-253.

Crant, J. M. 1996. The proactive personality scale as a predictor of entrepreneurial intentions. Journal of Small Business Management 34(3): 42-49.

Davidsson, P. 1995. Culture, structure and regional levels of entrepreneurship. Entrepreneurship and Regional Development 7(1): 41-62.

Davidsson, P., and M. Henkson. 2002. Determinants of the Prevalance of Start-ups and High-Growth Firms. Small Business Economics 19(2): 81-104.

Delmar, F., and P. Davidsson. 2000. Where do they come from?. Prevalence and characteristics of nascent entrepreneurs. Entrepreneurship and Regional Development 12(1): 1-23.

Díaz, D., D. Urbano, and R. Hernández. 2005. Teoría económica institucional y creación de empresas. Investigaciones Europeas de Dirección y Economía de la Empresa 21(3): 209-230.

Fayolle, A., and B. Gailly. 2005. Using the Theory of Planned Behaviour to Assess Entrepreneurship Teaching Programmes. Center for Research in Change, Innovation and Strategy of Louvain School of Management, Working Paper 05/2005.

Ferrando, P.J., L. Condon, and E. Chico. 2004. The convergent validity of acquiescence: an empirical study relating balanced scales and separate acquiescence scales. Personality and Individual Differences 37(7): 1331-1340.

Gnyawali, D. R., and D. S. Fogel. 1994. Environments for entrepreneurship development: key dimensions and research implications. Entrepreneurship Theory and Practice 18(4): 43-62.

Granovetter, M. 1983. The Strength of Weak Ties: A Network Theory Revisited. Sociological Theory 1: 201-233.

Granovetter, M. 1985. Economic Action and Social Structure: The Problem of Embeddedness. American Journal of Sociology 91(3): 481.

Greve, A. and J.W. Salaff. 2003. Social Networks and Entrepreneurship. Entrepreneurship Theory and Practice 28(1): 1-22

Grootaert, C., and T. v. Bastelaer. 2001. Understanding and measuring social capital: a synthesis of findings and recommendations from the social capital initiative. The World Bank, Social Capital Initiative, Working Paper $N^{o} 24$.

Guerrero, M., J. Rialp, and D. Urbano. 2008. The impact of desirability and feasibility on entrepreneurial intentions: A structural equation model. International Entrepreneurship and Management Journal 4(1): 35-50.

Guzmán, J. and F.J. Santos. 2001. The booster function and the entrepreneurial quality: an application to the province of Seville. Entrepreneurship \& Regional Development 13(3): 211-228.

Hayton, C., G. George, and S.A. Zahra. 2002. National Culture and Entrepreneurship: A review of behavioral research. Entrepreneurship Theory and Practice, 26.

Hmieleski, K. M., and A. C. Corbett. 2006. Proclivity for improvisation as a predictor of entrepreneurial intentions. Journal of Small Business Management 44(1): 45-63. 
Hoang, H. and B. Antoncic. 2003. Network-based research in entrepreneurship A critical review. Journal of Business Venturing 18(2): 165-187.

Hofstede, G. 1980. Culture's Consequences: International Differences in work-related values. Beverly Hills, CA: Sage Publications.

Hofstee, W.K.B., J.M.F. Ten Berge, and A.A.J. Hendriks. 1998. How to score questionnaires. Personality and Individual Differences, 25: 897-909.

Hurd, M. D. 1999. Anchoring and acquiescence bias in measuring assets in household surveys. Journal of Risk and Uncertainty 19(1), 111-136.

Jack, S.L. and A.R. Anderson. 2002. The effects of embeddedness on the entrepreneurial process. Journal of Business Venturing 17(5): 467-487.

Kennedy, J., J. Drennan, P. Renfrow, and B. Watson. 2003. Situational Factors and Entrepreneurial Intentions. Paper presented at the 16th Annual Conference of the Small Enterprise Association of Australia and New Zealand.

Kickul, J., and J.A. Zaper. 2000. Untying the knot: Do personal and organizational determinants influence entrepreneurial intentions?, Journal of Small Business and Entrepreneurship 15 (3): 5777.

Kim, P.H., H.E. Aldrich, L.A. Keister. 2006. Access (not) denied: the impact of financial, human, and cultural capital on entrepreneurial entry in the United States. Small Business Economics 27:5-22

Kolvereid, L. 1996. Prediction of employment status choice intentions. Entrepreneurship Theory and Practice 21(1): 47-57.

Kolvereid, L., and E. Isaksen. (2006). New business start-up and subsequent entry into self-employment, Journal of Business Venturing 21(6): 866-885.

Krueger, N. F. 2000. The cognitive infrastructure of opportunity emergence. Entrepreneurship Theory and Practice 24(3): 5-23.

Krueger, N. F. 2007. What lies beneath? The experiential essence of entrepreneurial thinking. Entrepreneurship Theory and Practice 31(1): 123-138.

Krueger, N. F., and D. V. Brazeal. 1994. Entrepreneurial potential and potential entrepreneurs. Entrepreneurship Theory and Practice 19(3): 91-104.

Krueger, N. F., M. D. Reilly, and A. L. Carsrud. 2000. Competing models of entrepreneurial intentions. Journal of Business Venturing 15(5-6): 411-432.

Kuratko, D. and R.D. Mathews. 2004. Note to Instructors CommunityWeb: An Internet Firm's Fight to Survive. Entrepreneurship Theory and Practice 28(3): 291-293.

Liñán, F. 2004. Intention-based models of entrepreneurship education. Piccola Impresa / Small Business 3: $11-35$.

Liñán, F., and F. J. Santos. 2007. Does social capital affect entrepreneurial intentions? International Advances in Economic Research 13(4): 443-453.

Liñán, F., and Y.-W. Chen. 2009. Development and cross-cultural application of a specific instrument to measure entrepreneurial intentions. Entrepreneurship Theory and Practice 33(3): 593-617.

Litwack, J. M. 1993. Issues in the creation of fiscal legality in the economies of the former USSR. Eastern Economic Journal 19(3): 335-345.

Luthje, C., and N. Franke. 2003. The making of an entrepreneur: testing a model of entrepreneurial intent among engineering students at MIT. $R \&$ D Management 33(2): 135-147.

Matthews, C. H., and S. B. Moser. 1996. A longitudinal investigation of the impact of family background and gender on interest in small firm ownership. Journal of Small Business Management 34(2): 2943.

Mazzarol, T., T. Volery, N. Doss, and V. Thein. 1999. Factors influencing small business start-ups. A comparison with previous research. International Journal of Entrepreneurial Behaviour \& Research 5(2): 48-63.

Mitchell, R. K., B. Smith, K. W. Seawright, and E. A. Morse. 2000. Cross cultural cognition and venture creation decision. Academy of Management Review 43(5): 974-993. 
Mitchell, R. K., L. Busenitz, T. Lant, P. P. Mcdougall, E. A. Morse, and J. B. Smith. 2002. Toward a theory of entrepreneurial cognition: Rethinking the people side of entrepreneurship research. Entrepreneurship Theory and Practice 27(2): 93-104.

Mitchell, R. K., L. W. Busenitz, B. Bird, C. M. Gaglio, J. S. McMullen, E. A. Morse. 2007. The central question in entrepreneurial cognition research 2007. Entrepreneurship Theory and Practice 31(1): $1-27$.

Mueller, S. and A. Tomas. 2001. Culture and Entrepreneurial Potential. A nine country study of locus of control and innovativeness . Journal Business Venturing 16(1): 51-75.

Naphiet, J. and S. Ghoshal. 1998. Social Capital, Intellectual Capital and the Organisational Advantage. Academy of Management Review 22(2): 242-266.

Nee, V. 1992. Organizational Dynamics of Market Transition: Hybrid Forms, Property Rights and Mixed Economy in China. Administrative Science Quarterly 37(1): 1-27.

Nee, V., and F. W. Young. 1991. Peasant Entrepreneurs in China's Second Economy: An Institutional Analysis. Economic Development and Cultural Change 39(2): 293-310.

North, D. C. 1990. Institutions, institutional change and economic performance. Cambridge: Cambridge University Press.

North, D. C. 2005. Understanding the process of economic change. Princeton: Princeton University Press. Nunnally, J.C. 1978. Psychometric Theory. $2^{\text {nd }}$ edition. N.Y: Mc.Graw Hill.

Peng, M., and S. V. Shekshnia. 2001. How entrepreneurs create wealth in transition economies. Academy of Management Executive 15(1): 95-110.

Peterman, N. E., and J. Kennedy. 2003. Enterprise education: Influencing students' perceptions of entrepreneurship. Entrepreneurship-Theory and Practice 28(2): 129-144.

Ray, J. J. 1979. Is the acquiescent response style not so mythical after all? Some results from a successful balanced F scale. Journal of Personality Assessment 43: 638-643.

Ray, J. J. 1983. Reviving the problem of acquiescent response bias. Journal of Social Psychology 121: 81-96.

Reynolds, P. D. 2005. Understanding Business Creation: Serendipity and Scope in Two Decades of Business Creation Studies. Small Business Economics 24: 359-364.

Robinson, P. B., D. V. Stimpson, J. Huefner, and H. K. Hunt. 1991. An attitude approach to the prediction of entrepreneurship. Entrepreneurship Theory and Practice 15(4): 13-31.

Roldán, J. L., and A. Leal. 2003. A validation test of an adaptation of the DeLone and McLean's model in the Spanish EIS field. In J. J. Cano (Ed.), Critical reflections on information systems. A systematic approach (pp. 66-84). Hershey, PA: Idea Group Publishing.

Rotefoss, B. and L. Kolvereid. 2005. Aspiring, nascent and fledgling entrepreneurs: an investigation of the business start-up process. Entrepreneurship \& Regional Development 17(2): 109-127.

Scherer, R. F., J. D. Brodzinsky, and F. A. Wiebe. 1991. Examining the relationship between personality and entrepreneurial career preference. Entrepreneurship and Regional Development 3: 195-206.

Shapero, A., and L. Sokol. 1982. Social dimensions of entrepreneurship. In C. A. Kent, D. L. Sexton and K. H. Vesper (Eds.), Encyclopedia of entrepreneurship (pp. 72-90). Englewood Cliffs (NJ): Prentice Hall.

Shook, C., D. Ketchen, G. Hult, K.M. Kacmar, 2004. An assessment of the use of structural equation models in strategic management research. Strategic Management Journal 25:397-404.

Simon, M., S.M. Houghton, and K. Aquino. 1999. Cognitive biases, risk perception, and venture formation: how individuals decide to start companies. Journal of Business Venturing 15:113-134.

Spilling, O., R. 1991. Entrepreneurship in a Culture Perspective. Entrepreneurship and Regional Development 3:33-48.

Stein, K. 2002. Individual perception of business contexts: The case of small-scale entepreneurs in Tanzania. Journal of Developmental Entrepreneurship 7(3): 283-305.

Takyiasiedu, S. 1993. Some Sociocultural Factors Retarding Entrepreneurial Activity in Sub-Saharan Africa. Journal of Business Venturing 8(2): 91-98. 
Thomas, A. S., and S. L. Muller. 2000. A case for comparative entrepreneurship: assessing the relevance of culture. Journal of International Business Studies 31(2): 287-301.

Thompson, E. R. 2009. Individual Entrepreneurial Intent: Construct Clarification and Development of an Internationally Reliable Metric. Entrepreneurship Theory and Practice 33(3): 669-694.

Tkachev, A., and L. Kolvereid. 1999. Self-employment intentions among Russian students. Entrepreneurship and Regional Development 11(3): 101-114.

Uphoff, N. 2000. Understanding social capital: learning from the analysis and experience of participation. In P. Dasgupta and I. Serageldin (Eds.), Social capital, a multifaceted perspective (pp. 215-249). Washington: The World Bank.

Urbano, D. 2006. New business creation in Catalonia : support measures and attitudes towards entrepreneurship. Barcelona: Generalitat de Catalunya.

Vaillant, Y. and E. Lafuente. 2007. Do different institutional frameworks condition the influence of local fear of failure and entrepreneurial examples over entrepreneurial activity? Entrepreneurship \& Regional Development 19(4): 313-337.

Veciana, J. M. 1999. Creación de empresa como programa de investigación científica. Revista Europea de Dirección y Economía de la Empresa 8(3): 11-36.

Veciana, J. M., M. Aponte, and D. Urbano, 2005. University students' attitudes towards entrepreneurship: a two countries comparison. International Entrepreneurship and Management Journal 1(2): 165182.

Walstad, W. B., and M. L. Kourilsky. 1998. Entrepreneurial attitudes and knowledge of black youth. Entrepreneurship Theory and Practice 23(2): 5-18.

Westhead, P. 1995. Exporting and non-exporting small firms in Great Britain. A matched pairs comparison. International Journal of Entrepreneurial Behaviour and Research 1(2): 6-30.

Woolcock, M. and D. Narayan. 2000. Social Capital: Implications for Development Theory, Research, and Policy. World Bank Research Observer 15(2): 225-249.

Zahra, S. A., D. F. Jennings, and D. F. Kuratko. 1999. The antecedents and consequences of firm-level entrepreneurship: The state of the field. Entrepreneurship Theory and Practice 24(2): 45-63.

Zahra, S.A. and J. Wiklund. 2002. Top management team characteristics and entrepreneurial resource recombinations among new ventures. Mimeo. Jonkoping International Business School, Jonkoping, Sweden. Retrieved from http://www.sbaer.uca.edu/research/icsb/2000/pdf/101.PDF on June, 11th 2008.

Zhao, H., G. E. Hills, and S. E. Siebert, 2005. The mediating role of self-efficacy in the development of entrepreneurial intentions. Journal of Applied Psychology 90(6): 1265-1272. 


\section{Appendix 1. Questionnaire items (original in Spanish)}

A. Indicate your level of agreement with the following statements about the Entrepreneurial Activity from 1 (total disagreement) to 7 (total agreement).

A01.- Starting a firm and keeping it viable would be easy for me

A02.- A career as an entrepreneur is totally unattractive to me

A03.- My friends would approve of my decision to start a business

A04.- I am ready to do anything to be an entrepreneur

A05.- I believe I would be completely unable to start a business

A06.- I will make every effort to start and run my own business

A07.- I am able to control the creation process of a new business

A08.- My immediate family would approve of my decision to start a business

A09.- I have serious doubts about ever starting my own business

A10.- If I had the opportunity and resources, I would love to start a business

A11.- My colleagues would approve of my decision to start a business

A12.- Amongst various options, I would rather be anything but an entrepreneur

A13.- I am determined to create a business venture in the future

A14.- If I tried to start a business, I would have a high chance of being successful

A15.- Being an entrepreneur would give me great satisfaction

A16.- It would be very difficult for me to develop a business idea

A17.- My professional goal is to be an entrepreneur

A18.- Being an entrepreneur implies more advantages than disadvantages to me

A19.- I have a very low intention of ever starting a business

A20.- I know all about the practical details needed to start a business

\begin{tabular}{l|l|l|l|l|l|l|}
\hline $\mathbf{1}$ & $\mathbf{2}$ & $\mathbf{3}$ & $\mathbf{4}$ & $\mathbf{5}$ & $\mathbf{6}$ & $\mathbf{7}$ \\
\hline$\square$ & $\square$ & $\square$ & $\square$ & $\square$ & $\square$ & $\square$ \\
$\square$ & $\square$ & $\square$ & $\square$ & $\square$ & $\square$ & $\square$ \\
$\square$ & $\square$ & $\square$ & $\square$ & $\square$ & $\square$ & $\square$ \\
$\square$ & $\square$ & $\square$ & $\square$ & $\square$ & $\square$ & $\square$ \\
$\square$ & $\square$ & $\square$ & $\square$ & $\square$ & $\square$ & $\square$ \\
$\square$ & $\square$ & $\square$ & $\square$ & $\square$ & $\square$ & $\square$ \\
$\square$ & $\square$ & $\square$ & $\square$ & $\square$ & $\square$ & $\square$ \\
$\square$ & $\square$ & $\square$ & $\square$ & $\square$ & $\square$ \\
$\square$ & $\square$ & $\square$ & $\square$ & $\square$ & $\square$ & $\square$ \\
$\square$ & $\square$ & $\square$ & $\square$ & $\square$ & $\square$ & $\square$ \\
$\square$ & $\square$ & $\square$ & $\square$ & $\square$ & $\square$ \\
$\square$ & $\square$ & $\square$ & $\square$ & $\square$ & $\square$ & $\square$ \\
$\square$ & $\square$ & $\square$ & $\square$ & $\square$ & $\square$ & $\square$ \\
$\square$ & $\square$ & $\square$ & $\square$ & $\square$ & $\square$ \\
$\square$ & $\square$ & $\square$ & $\square$ & $\square$ & $\square$ & $\square$ \\
$\square$ & $\square$ & $\square$ & $\square$ & $\square$ & $\square$ & $\square$ \\
$\square$ & $\square$ & $\square$ & $\square$ & $\square$ & $\square$ \\
$\square$ & $\square$ & $\square$ & $\square$ & $\square$ & $\square$ & $\square$ \\
$\square$ & $\square$ & $\square$ & $\square$ & $\square$ & $\square$ & $\square$ \\
$\square$ & $\square$ & $\square$ & $\square$ & $\square$ & $\square$
\end{tabular}

C. Indicate your level of agreement with the following sentences about the values society put on entrepreneurship from 1 (total disagreement) to 7 (total agreement).

C1.- My immediate family values entrepreneurial activity above other activities and careers

C2.- The culture in my country is highly favourable towards entrepreneurial activity

C3.- The entrepreneur's role in the economy is generally undervalued in my country

C4.- My friends value entrepreneurial activity above other activities and careers

C5.- Most people in my country consider it unacceptable to be an entrepreneur

C6.- In my country, entrepreneurial activity is considered to be worthwhile, despite the risks

C7.- My colleagues value entrepreneurial activity above other activities and careers

C8.- It is commonly thought in my country that entrepreneurs take advantage of others

\begin{tabular}{|l|l|l|l|l|l|l|}
\hline 1 & 2 & 3 & 4 & 5 & 6 & 7 \\
\hline
\end{tabular}

$\square \square \square \square \square \square \square$

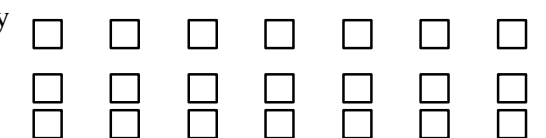


Table 1: Main regional characteristics

\begin{tabular}{llrrrrr}
\hline \multicolumn{1}{c}{ Indicator } & \multicolumn{1}{c}{ Regional Context } & Spain & \multicolumn{2}{c}{ Catalonia } & \multicolumn{2}{c}{ Andalucía } \\
\hline Geographical & Localization & & \multicolumn{2}{c}{ Northeast } & \multicolumn{2}{c}{ South } \\
Socio-demographical & Population (total number) & 44.708 .964 & 7.134 .697 & $15.96 \% *$ & 7.975 .672 & $17.84 \% *$ \\
& Male & 22.100 .466 & 3.543 .706 & & 3.958 .565 & \\
& Female & 22.608 .498 & 3.590 .991 & & 4.017 .107 & \\
& Economically Active Population & 37.733 .900 & 6.023 .000 & $15.96 \% *$ & 6.576 .000 & $17.43 \% *$ \\
Economical & GDP Per capita (Euros) & 22.150 & 26.124 & 4 th* & 17.250 & 17 th* \\
& GDP Growth rate (2000-2006) & 3.90 & 3.80 & Lower* & 3.90 & Higher* \\
& Total Employment & 20.724 .900 & 3.691 .900 & $17.81 \% *$ & 3.016 .200 & $14.55 \% *$ \\
Education & Universities & 73 & 12 & $17.43 \% *$ & 10 & $13.69 \% *$ \\
& Students & 1.433 .016 & 182.258 & $12.72 \% *$ & 230.621 & $16.09 \% *$ \\
Entrepreneurial & Enterprises (number) & 3.174 .393 & 578.340 & $18.22 \% *$ & 486.674 & $15.33 \% *$ \\
& New Enterprises (number) & 415.275 & 77.656 & $18.70 \% *$ & 60.215 & $14.50 \% *$ \\
& Regional Supports provided by & Government & Generalitat of Catalonia & Junta of Andalusia \\
\hline
\end{tabular}

* Regional Context presence vs. Spanish Data

Source: Last data published in 2006 by the INE (Spanish National Statistics Institute) 
Table 2: Main details of surveyed universities

\begin{tabular}{|c|c|c|c|}
\hline \multicolumn{2}{|c|}{ Description } & $\begin{array}{l}\text { Autonomous University of Barcelona } \\
\text { (UAB) }\end{array}$ & University of Seville (USE) \\
\hline \multicolumn{2}{|c|}{ General Information Focus } & \multicolumn{2}{|c|}{$\begin{array}{l}\text { Humanities, Social Sciences, Health Sciences, Experimental Sciences and } \\
\text { Engineering. }\end{array}$} \\
\hline & Age & 39 years 5 & 502 years \\
\hline & Nature & Public University & Public University \\
\hline & University size & 31660 undergraduate & 59892 undergraduate \\
\hline \multirow[t]{3}{*}{ Entrepreneurial Side } & Educational programs & $\begin{array}{l}\text { Extracurricular start-up course and } \\
\text { Doctoral program in business creation }\end{array}$ & Extracurricular start-up course \\
\hline & Spin-offs & 18 technological and biotechnological & 13 technological \\
\hline & Spillovers from $90 \mathrm{~s}$ & 14653 research papers $\quad \varepsilon$ & 8444 research papers \\
\hline \multirow[t]{6}{*}{ Technical Details } & Criteria & \multicolumn{2}{|c|}{$\begin{array}{l}\text { University students enrolled in Business Administration and Economics (in the } \\
\text { two final years). }\end{array}$} \\
\hline & Date of field work & \multicolumn{2}{|c|}{ October and November, 2006.} \\
\hline & Population & \multicolumn{2}{|c|}{3811 university students (2338 UAB students and 1473 USE students) } \\
\hline & Sample Size & \multicolumn{2}{|c|}{549 university students ( 300 UAB and 249 USE) } \\
\hline & Sample Error & \multicolumn{2}{|c|}{ $\pm 3.87 \%$} \\
\hline & Confidence Level & \multicolumn{2}{|l|}{$95 \%(\mathrm{Z}=1.96, \mathrm{p}=\mathrm{q}=0.5)$} \\
\hline
\end{tabular}


Table 3: Factor analysis entrepreneurial intention (Rotated Factor matrix)

\begin{tabular}{|c|c|c|c|c|c|c|}
\hline \multirow[t]{2}{*}{ Items } & \multicolumn{4}{|c|}{ Factor } & \multicolumn{2}{|c|}{ Communalities } \\
\hline & 1 & 2 & 3 & 4 & Initial & Extraction \\
\hline $\mathrm{a} 01$ & & & .601 & & .330 & .395 \\
\hline a2Rev & & & & .517 & .195 & .269 \\
\hline $\mathrm{a} 03$ & & .854 & & & .568 & .666 \\
\hline $\mathrm{a} 04$ & .539 & & & & .332 & .366 \\
\hline a06 & .603 & & & & .508 & .545 \\
\hline $\mathrm{a} 07$ & & & .484 & & .427 & .441 \\
\hline $\mathrm{a} 08$ & & .607 & & & .415 & .446 \\
\hline a11 & & .897 & & & .635 & .810 \\
\hline a12Rev & & & & .618 & .353 & .480 \\
\hline a13 & .689 & & & & .611 & .680 \\
\hline a14 & & & .642 & & .455 & .554 \\
\hline a15 & .424 & & & .514 & .541 & .633 \\
\hline a16Rev & & & .572 & & .247 & .386 \\
\hline a17 & .541 & & & & .530 & .537 \\
\hline a18 & & & & .327 & .367 & .387 \\
\hline $\mathrm{a} 20$ & & & .501 & & .241 & .279 \\
\hline Cronbach alpha & .809 (4 items) & .818 & .727 & .722 (4 items) & & \\
\hline
\end{tabular}

Note: Extraction method: principal axis factorization.

Rotation method: Oblimin Normalization with Kaiser.

Rotation converged after 12 iterations. Loadings below 0.30 not shown. 
Table 4: Factor analysis social variables (Rotated Factor matrix)

\begin{tabular}{lcccc}
\hline & \multicolumn{2}{c}{ Factor } & \multicolumn{2}{c}{ Communalities } \\
\cline { 2 - 5 } Items & 1 & 2 & Initial & Extraction \\
\hline c1 & .520 & &, 251 &, 283 \\
c2 & .302 & .488 &, 279 &, 383 \\
c3Rev & & .547 &, 162 &, 290 \\
c4 & .821 & &, 543 &, 656 \\
c5Rev & & .470 &, 138 &, 213 \\
c6 & .325 & .428 &, 281 &, 339 \\
c7 & .858 & &, 554 &, 716 \\
\hline Cronbach alpha & $.762(3$ items $)$ & $.572(4$ items $)$ & & \\
\hline
\end{tabular}

Note: Extraction method: principal axis factorization.

Rotation method: Oblimin Normalization with Kaiser.

Rotation converged after 5 iterations. Loadings below 0.30 not shown. 
Table 5: T-test for equality of means

\begin{tabular}{|c|c|c|c|c|c|c|c|c|c|}
\hline \multicolumn{5}{|c|}{$\begin{array}{l}\text { Levene's test } \\
\text { for equality of } \\
\text { variances }\end{array}$} & \multicolumn{5}{|c|}{ t-test for equality of means } \\
\hline & \multirow[t]{2}{*}{$\begin{array}{r}\text { Equal } \\
\text { Variances } \\
\text { Assumed }\end{array}$} & \multirow[t]{2}{*}{$\mathrm{F}$} & \multirow[t]{2}{*}{ Sig. } & \multirow[t]{2}{*}{$\mathrm{T}$} & \multirow[t]{2}{*}{ Df } & \multirow[t]{2}{*}{$\begin{array}{l}\text { Sig. }(2- \\
\text { tailed) }\end{array}$} & \multirow[t]{2}{*}{$\begin{array}{c}\text { Mean } \\
\text { difference }\end{array}$} & \multicolumn{2}{|c|}{$\begin{array}{l}95 \% \text { confidence } \\
\text { interval of the } \\
\text { difference }\end{array}$} \\
\hline & & & & & & & & lower & Upper \\
\hline \multirow[t]{2}{*}{ Entrepreneurial Intention } & Yes & 4,111 & 0,043 & 0,339 & 533 & 0,735 & 0,027 & 0,078 & $-0,127$ \\
\hline & No & & & 0,336 & 483,019 & 0,737 & $\mathbf{0 , 0 2 7}$ & $\mathbf{0 , 0 7 9}$ & $-0,129$ \\
\hline \multirow{2}{*}{$\begin{array}{l}\text { Attitude towards the } \\
\text { behaviour }\end{array}$} & Yes & 2,087 & 0,149 & $-0,996$ & 533 & $\mathbf{0 , 3 2 0}$ & $-0,073$ & $\mathbf{0 , 0 7 3}$ & $-0,216$ \\
\hline & No & & & $-0,986$ & 479,741 & 0,325 & $-0,073$ & 0,074 & $-0,218$ \\
\hline \multirow[t]{2}{*}{ P Behavioural control } & Yes & 2.303 & .130 & 2.036 & 533 & .042 & .15507 & .00546 & .30469 \\
\hline & No & & & 2.020 & 486.544 & .044 & .15507 & .00424 & .30590 \\
\hline \multirow[t]{2}{*}{ Subjective Norms } & Yes & 0,027 & 0,869 & 0,985 & 533 & 0,325 & $\mathbf{0 , 0 8 1}$ & 0,082 & $-0,080$ \\
\hline & No & & & 0,984 & 500,639 & 0,326 & 0,081 & 0,082 & $-0,080$ \\
\hline \multirow{2}{*}{$\begin{array}{l}\text { Closer Valuation } \\
\text { Entrepreneurship }\end{array}$} & Yes & 0,355 & 0,552 & 0,591 & 541 & $\mathbf{0 , 5 5 5}$ & 0,047 & $\mathbf{0 , 0 7 9}$ & $-0,109$ \\
\hline & No & & & 0,593 & 524,037 & 0,554 & 0,047 & 0,079 & $-0,108$ \\
\hline \multirow{2}{*}{$\begin{array}{l}\text { Social valuation } \\
\text { Entrepreneurship }\end{array}$} & Yes & 3.996 & .046 & 7.279 & 541 & .000 & .46078 & .33643 & .58513 \\
\hline & No & & & 7.162 & 478.240 & .000 & .46078 & .33436 & .58719 \\
\hline \multirow[t]{2}{*}{ Labour Experience (i3) } & Yes & 412.443 & .000 & 10.137 & 547 & .000 & .350 & .282 & .418 \\
\hline & No & & & 9.706 & 390.692 & .000 & .350 & .279 & .421 \\
\hline \multirow[t]{2}{*}{ SelfEmpl. Experience (i4) } & Yes & 29.464 & .000 & 2.634 & 547 & .009 & .052 & .013 & .091 \\
\hline & No & & & 2.749 & 504.659 & .006 & .052 & .015 & .089 \\
\hline \multirow[t]{2}{*}{ Role Model (i5Family) } & Yes & 11.509 & .001 & 1.831 & 547 & .068 & .076 & -.006 & .158 \\
\hline & No & & & 1.825 & 521.304 & .069 & .076 & -.006 & .159 \\
\hline \multirow[t]{2}{*}{ Role Model (i5Friends) } & Yes & 2.400 & .122 & -1.747 & 547 & .081 & -.075 & -.159 & .009 \\
\hline & No & & & -1.746 & 527.343 & .081 & -.075 & -.159 & .009 \\
\hline \multirow[t]{2}{*}{ Role Model (i5Boss) } & Yes & 95.195 & .000 & 4.932 & 547 & .000 & .195 & .117 & .273 \\
\hline & No & & & 5.008 & 546.789 & .000 & .195 & .119 & .272 \\
\hline \multirow[t]{2}{*}{ Role Model (i5Others) } & Yes & 26.629 & .000 & 2.521 & 547 & .012 & .094 & .021 & .168 \\
\hline & No & & & 2.550 & 544.770 & .011 & .094 & .022 & .167 \\
\hline \multirow[t]{2}{*}{ Age (i11) } & Yes & 1.791 & .181 & -.541 & 516 & .589 & -.152 & -.704 & .400 \\
\hline & No & & & -.532 & 458.216 & .595 & -.152 & -.713 & .409 \\
\hline \multirow[t]{2}{*}{ Gender (i12) } & Yes & 5.148 & .024 & 1.318 & 524 & .188 & .057 & -.028 & .143 \\
\hline & No & & & 1.316 & 501.370 & .189 & .057 & -.028 & .143 \\
\hline \multirow[t]{2}{*}{ Immigration (i13) } & Yes & 17,311 &, 000 & $-2,122$ & 501 & 0,034 & $-0,106$ & 0,050 & $-0,204$ \\
\hline & No & & & $-2,085$ & 437,776 & 0,038 & $-0,106$ & 0,051 & $-0,205$ \\
\hline \multirow{2}{*}{$\begin{array}{l}\text { Knowledge of formal } \\
\text { support measures }\end{array}$} & Yes & 0,521 & 0,471 & $-2,283$ & 541 & $\mathbf{0 , 0 2 3}$ & $-0,245$ & 0,107 & $-0,455$ \\
\hline & No & & & $-2,296$ & 529,346 & 0,022 & $-0,245$ & 0,107 & $-0,454$ \\
\hline
\end{tabular}


Table 6: Reliability and Convergent Validity Analysis

\begin{tabular}{|c|c|c|c|c|c|c|c|c|c|c|}
\hline & & & & & Reliability & Analysis & & & & \\
\hline Var & riables & Items & Factor & r Analysis & Crophosh' & Item to & & nvergent & alidity $\mathrm{A}$ & lysis \\
\hline & & & & & & & A4 & A6 & A13 & A17 \\
\hline & & $\mathrm{A} 4$. & & & & $0.722^{* * * *}$ & 1.000 & $0.460^{* * * *}$ & $0.485^{\text {**** }}$ & $0.392^{* * * *}$ \\
\hline & 己ี & A6. & KMO & 0.763 & & $0.787^{* * * *}$ & $0.460^{* * *}$ & 1.000 & $0.587^{* * * *}$ & $0.490^{* * * *}$ \\
\hline 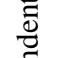 & $\stackrel{0}{0}$ & A13. & $X^{2}$ & 766.929 & 0.809 & $0.862^{* * * *}$ & $0.485^{\text {**** }}$ & $0.587^{* * *}$ & 1.000 & $0.686^{* * * *}$ \\
\hline गे & & A 17. & & & & $0.819^{* * *}$ & $0.392^{* * *}$ & $0.490^{* * *}$ & $0.686^{* * *}$ & 1.000 \\
\hline & & & & & & & A12Rev & A15 & A18 & \\
\hline & & "A12Rev. & KMO & 0.667 & & $0.810^{* * * *}$ & 1.000 & $0.509^{* * * *}$ & $0.395^{* * *}$ & \\
\hline & & A15. & $X^{2}$ & 344.723 & 0.724 & $0.840^{* * * *}$ & $0.509^{* * * *}$ & 1.000 & $0.507^{* * *}$ & \\
\hline & 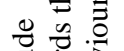 & A18. & & 0.000 & & $0.761^{* * * *}$ & $0.395^{* * * *}$ & $0.507^{* * *}$ & 1.000 & \\
\hline & 《 & & & & & & A3 & A8 & A11 & \\
\hline & & A3. & & 0692 & & $0.857^{* * * *}$ & 1.000 & $0.507^{* * *}$ & $0.717^{* * *}$ & \\
\hline &.$\frac{\tilde{U}}{0}$ & A8. & $\begin{array}{l}X^{2} \\
\text { Sig }\end{array}$ & $\begin{array}{r}641.549 \\
0000\end{array}$ & 0.818 & $0.831^{* * * *}$ & $0.507^{* * * *}$ & 1.000 & $0.595^{* * *}$ & \\
\hline & & A11. & & & & $0.888^{* * * *}$ & $0.717^{\text {**** }}$ & $0.595^{* * *}$ & 1.000 & \\
\hline & & & & & & & A1 & A7 & A14 & A20 \\
\hline & & A1. & & & & $0.719^{* * * *}$ & 1.000 & $0.395^{* * *}$ & $0.456^{* * * *}$ & $0.297^{* * * *}$ \\
\hline ల్ & $\stackrel{\Xi}{D} \overline{0}$ & A7. & KMO & 0.749 & & $0.736^{* * * *}$ & $0.395^{* * * *}$ & 1.000 & $0.449^{* * * *}$ & $0.371^{* * * *}$ \\
\hline 区ี & 氙 芯 & A14. & $\begin{array}{l}X^{2} \\
\operatorname{Sig}\end{array}$ & 404.823 & 0.712 & $0.760^{* * * *}$ & $0.456^{* * *}$ & $0.449^{* * *}$ & 1.000 & $0.376^{* * *}$ \\
\hline$\Xi$ & $\sim \bar{D}$ & A 20. & & & & $0.732^{* * * *}$ & $0.297^{* * *}$ & $0.371^{* * *}$ & $0.376^{* * *}$ & 1.000 \\
\hline & & & & & & & $\mathrm{C} 1$ & $\mathrm{C} 4$ & C7 & \\
\hline & ธี & C1. & & & & $0.758^{* * * *}$ & 1.000 & $0.447^{\text {*** }}$ & $0.405^{* * *}$ & \\
\hline & 可 & C4. & $X^{2}$ & $\begin{array}{c}0.054 \\
519.729\end{array}$ & 0.762 & $0.866^{\text {**** }}$ & $0.447^{* * * *}$ & 1.000 & $0.714^{* * * *}$ & \\
\hline & $\sqrt{\frac{\pi}{2}}$ & C7. & Sig & 0.000 & & $0.852^{* * * *}$ & $0.405^{* * *}$ & $0.714^{* * *}$ & 1.000 & \\
\hline & & & & & & & $\mathrm{C} 2$ & C6 & & \\
\hline & 조 홍 & C2. & KMO & 0.500 & & $0.870^{* * * *}$ & 1.000 & $0.456^{* * *}$ & & \\
\hline & ల్ & & & 126.705 & 0.624 & & & & & \\
\hline & & C6. & Sig & 0.000 & & $0.836^{* * * *}$ & $0.456^{* * *}$ & 1.000 & & \\
\hline
\end{tabular}

Note: * Reversion of items was performed through the following transformation: $1 \rightarrow 7,2 \rightarrow 6,3 \rightarrow 5,4 \rightarrow 4,5 \rightarrow 3,6 \rightarrow 2$ and $7 \rightarrow 1$. ${ }^{* * *} \mathrm{p}<0.01 ;{ }^{* *} \mathrm{p}<0.05 ;{ }^{* *} \mathrm{p}<0.10$ 
Table 7: Factor loadings for the structural equation model

\begin{tabular}{lcc}
\hline \multicolumn{1}{c}{ Construct } & Items & Loadings \\
\hline Entrepreneurial intention & A04 & 0.6994 \\
& A06 & 0.7955 \\
& A13 & 0.8774 \\
Attitude towards the behaviour & A17 & 0.8170 \\
& A12-rev- & 0.7609 \\
Subjective Norms & A15 & 0.8665 \\
& A18 & 0.7806 \\
Perceived Behavioural Control & A03 & 0.8241 \\
& A08 & 0.8414 \\
& A11 & 0.9007 \\
Closer Valuation & A01 & 0.7251 \\
& A07 & 0.7757 \\
Social Valuation & A14 & 0.7949 \\
& A20 & 0.6389 \\
& C1 & 0.8095 \\
& C4 & 0.8363 \\
& C7 & 0.8160 \\
& C2 & 0.8306 \\
\hline
\end{tabular}


Figure 1: Entrepreneurial intention model with hypotheses

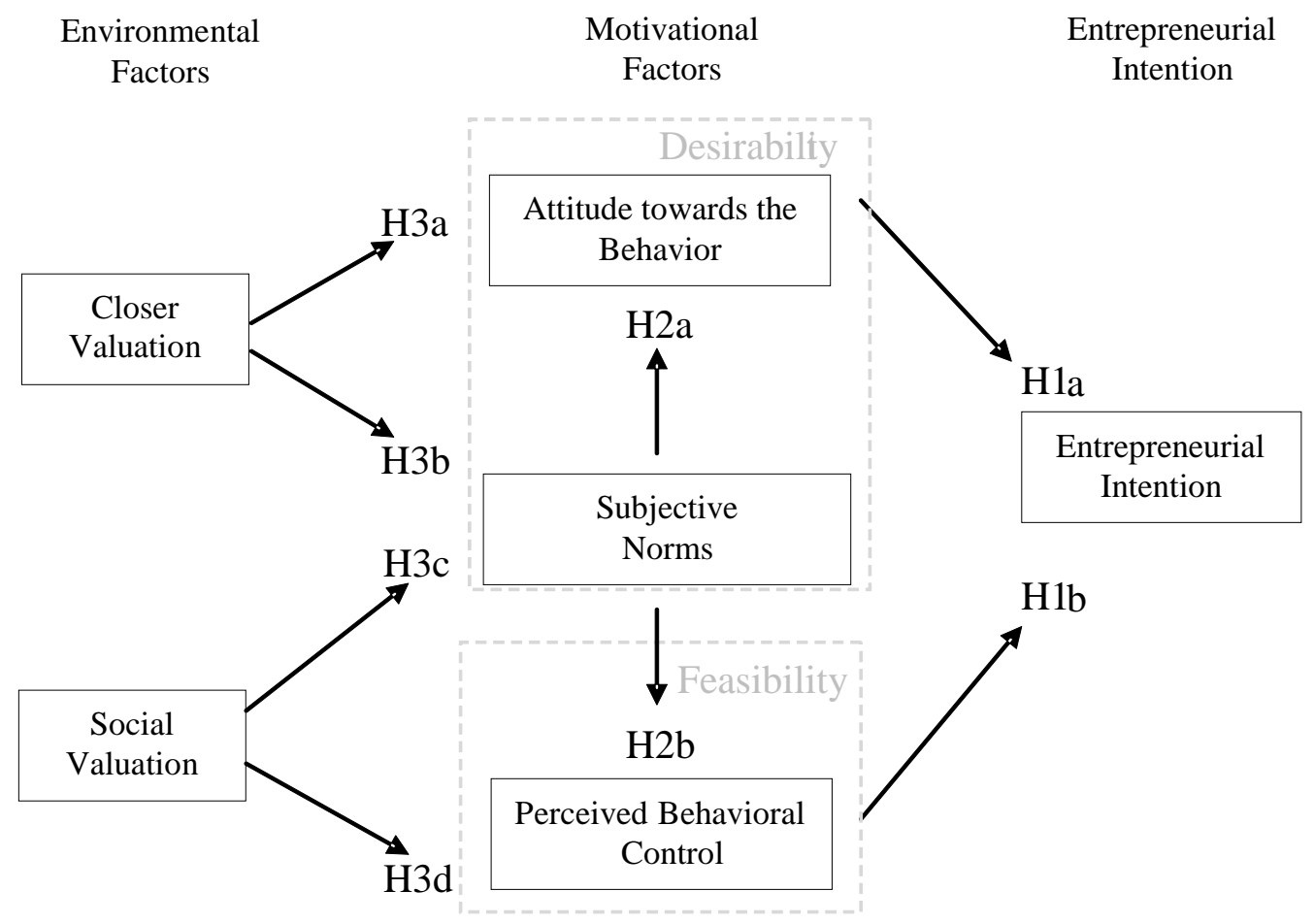


Figure 2: Results for the joint sample

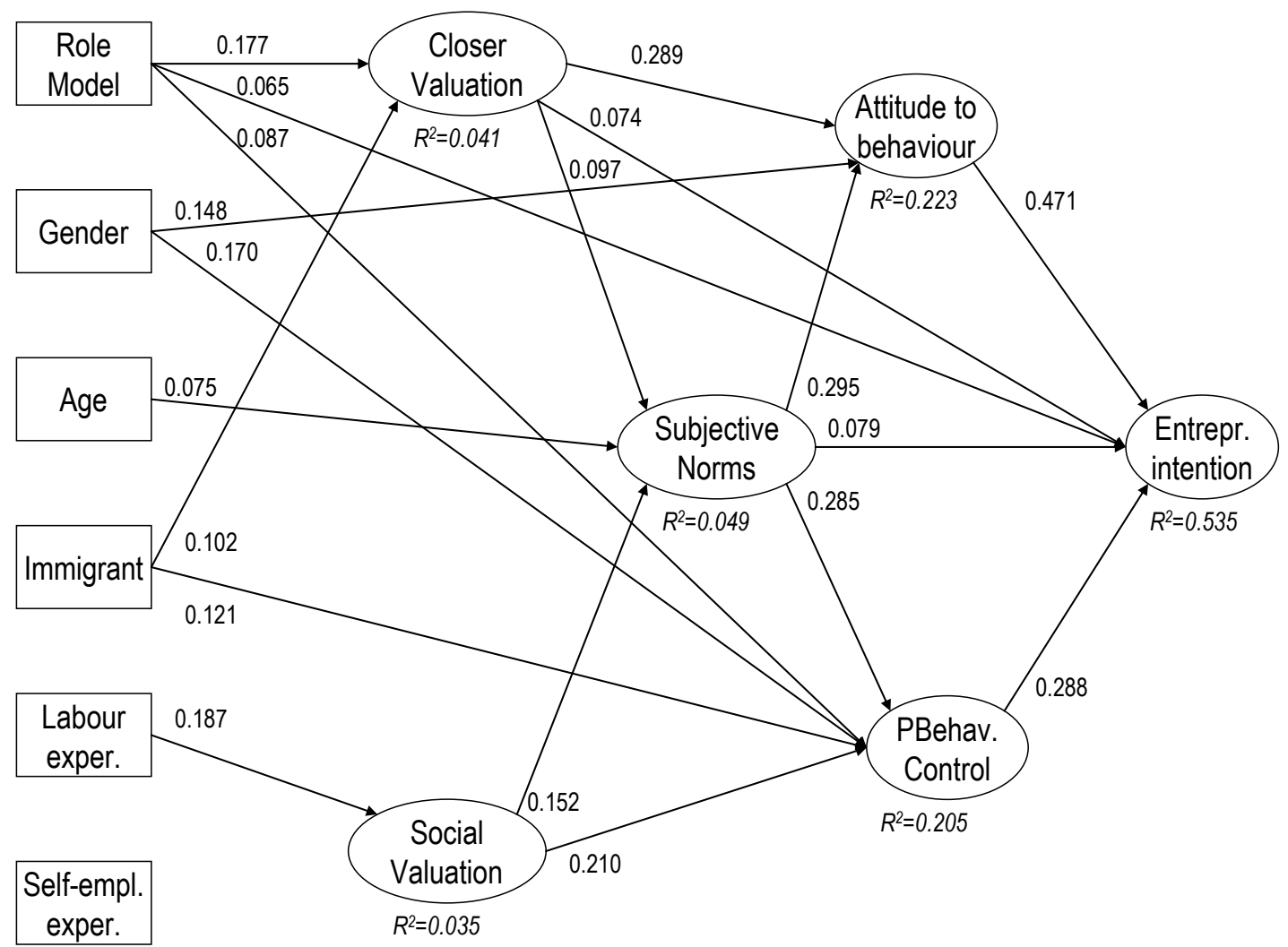

Note: Only significant $(\mathrm{p}<0.05)$ path coefficients are shown. 
Figure 3: Results for the Catalonian sub-sample

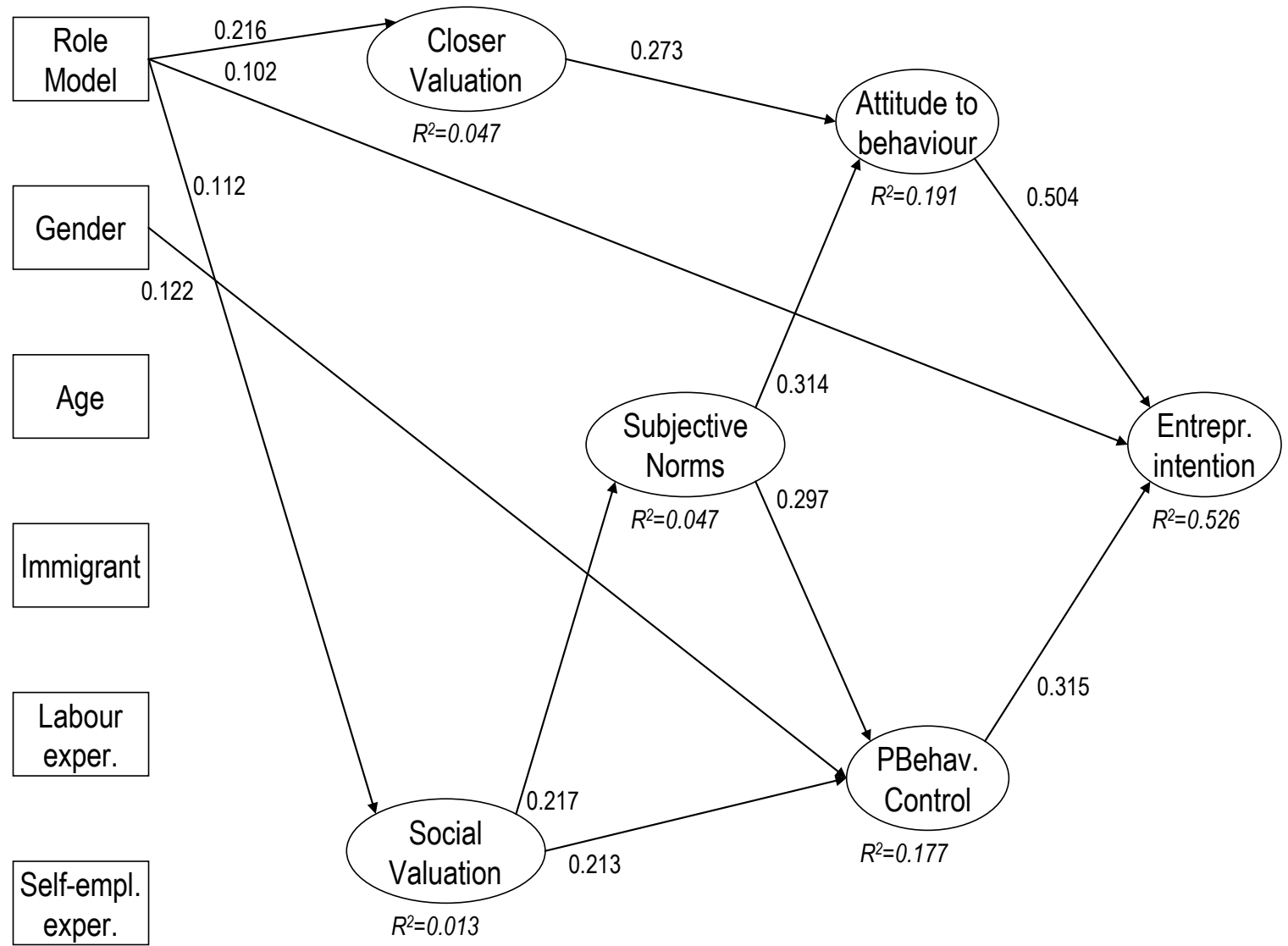

Note: Only significant $(\mathrm{p}<0.05)$ path coefficients are shown. 
Figure 4: Results for the Andalusian sub-sample

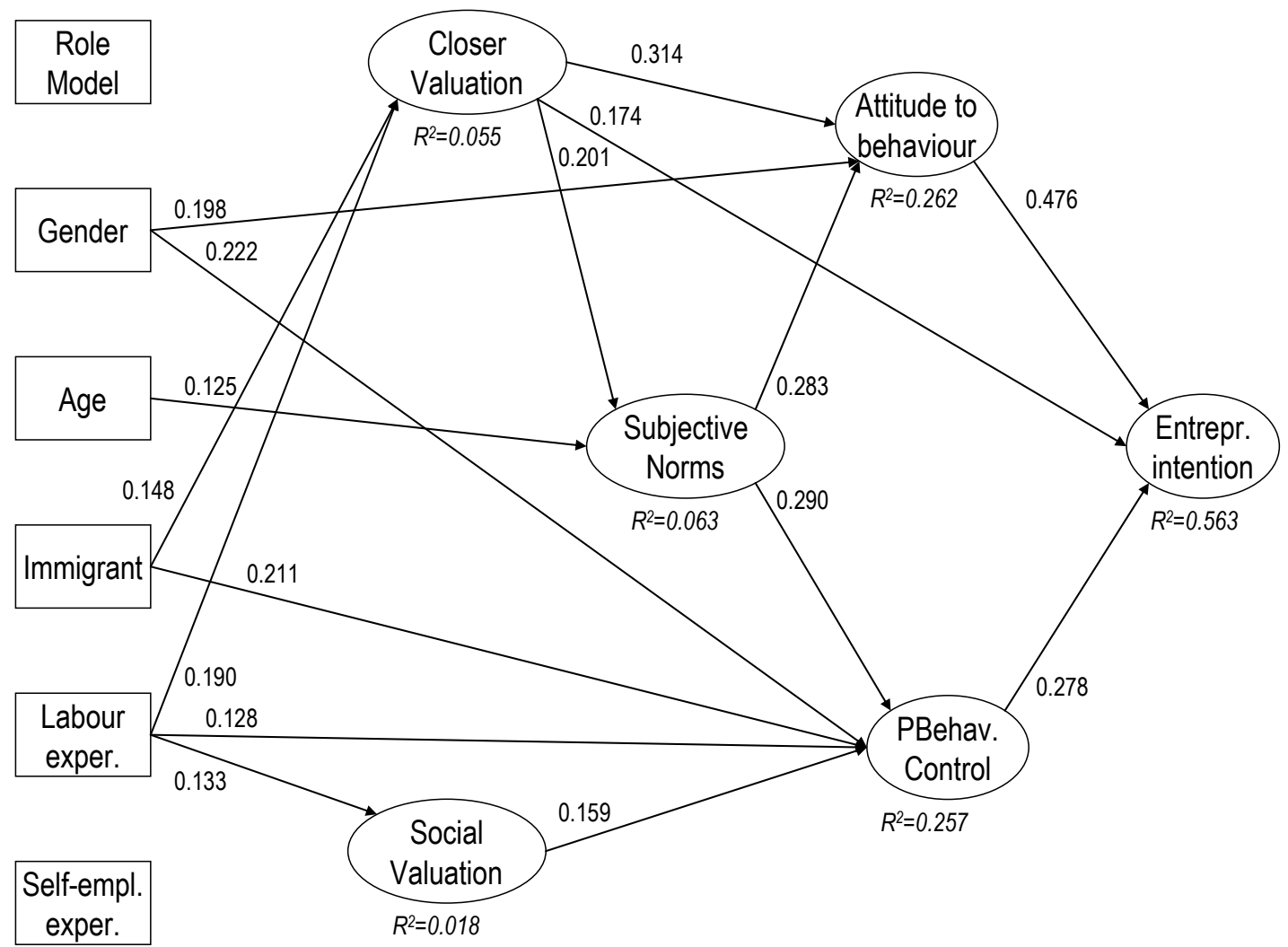

Note: Only significant $(\mathrm{p}<0.05)$ path coefficients are shown. 